\title{
Effect of Pretreatment with a High Fat Diet on the Gastric Inhibitory Polypeptide and Insulin Responses to Oral Triolein and Glucose in Rats
}

\author{
S. M. Hampton, P. Kwasowski, K. Tan, L. M. Morgan and V. Marks \\ Division of Clinical Biochemistry, Department of Biochemistry, University of Surrey, Guildford, Surrey, UK
}

\begin{abstract}
Summary. Male Wistar rats were pretreated with $3 \mathrm{ml}$ triolein orally for 4 days in addition to their normal diet. A similar control group were allowed free access to normal laboratory food. When given an oral fat load $(1 \mathrm{ml}$ triolein) plasma gastric inhibitory polypeptide (GIP) and triglyceride levels were significantly higher in the fat pretreated group. Inhibition of fat-stimulated GIP release by exogenous insulin was demonstrated in the untreated control group (plasma GIP: $663 \pm 49$ versus $853 \pm 92 \mathrm{ng} / 1$, mean \pm SEM $p<0.025$ ), but pretreatment with an oral fat load abolished this effect (plasma GIP: $1008 \pm 95$ versus $1116 \pm 100 \mathrm{ng} / \mathrm{l}, p$ NS). Plasma glucose levels were significantly higher in fat pretreated rats given oral fat and intraperitoneal insulin compared with untreated
\end{abstract}

controls (plasma glucose nadir $2.6 \pm 0.48$ versus $1.6 \pm 0.15$ $\mathrm{mmol} / \mathrm{l}, p<0.05$ ). Fat-pretreated rats showed significantly higher insulin and glucose levels compared with the untreated rats when given oral glucose (plasma insulin: $6.2 \pm 1.2$ versus $2.5 \pm 0.59 \mu \mathrm{g} / \mathrm{l}, p<0.01$; plasma glucose: $10.2 \pm 0.39$ versus $8.9 \pm 0.41 \mathrm{mmol} / 1, p<0.025$ ). Pretreatment of rats on a high fat diet causes (1) increased GIP secretion in response to an oral fat load, (2) abolition of the feed-back inhibition of exogenous insulin on fat-stimulated GIP release, and (3) some degree of insulin resistance.

Key words: GIP, insulin, triolein, dietary adaptation.
The concept that the gut can modify insulin secretion has been well established since experiments in 1964 by McIntyre et al. [1] demonstrated that intrajejunally administered glucose led, on a molar basis, to more than twice as much insulin release as intravenous glucose.

The intestinal hormone gastric inhibitory polypeptide (GIP) is a potent stimulator of glucose-induced insulin secretion [2] and is currently thought to be one of the major endocrine components of the entero-insular axis. GIP is released after ingestion of glucose $[2,3]$ amino acids [4] or fat $[2,5]$, the latter being especially potent. Exogenous insulin [2,6] and C-peptide [7] have been shown to inhibit fat-induced GIP release and may play a physiological role in the regulation of GIP secretion.

Obesity in man is characterised biochemically by basal hyperinsulinaemia and an exaggerated insulinaemic response to glucose and most other insulinotropic stimuli [8]. The cause of the hyperinsulinaemia is still controversial but it could be due, at least in part, to an overactive enteroinsular-axis. Exaggerated GIP responses have been observed after a mixed meal in obese subjects [9] and exogenous insulin fails to inhibit fatstimulated GIP in this group [10]. However, the composition of the diet preceding the test appears to be a fac- tor in the altered GIP response. Willms et al. [11], for example, found that 5 days of calorie restriction abolished the exaggerated GIP response to a fat or mixed meal in obese subjects, suggesting that a previously high calorie intake might have been responsible for the excessive GIP production.

We have therefore investigated the effect of pretreatment with fat supplements on fat and glucose-induced GIP release in rats. The inhibition of fat-stimulated GIP release by exogenous insulin was also investigated.

\section{Materials and Methods}

Male Wistar rats weighing between 240 and $290 \mathrm{~g}$ were used. The 160 rats were divided into two equal groups. The first (fat-pretreated group) was given $3 \mathrm{ml}$ triolein $(24 \mathrm{kcal}$ ) a day orally for 4 days before the experiment as well as being allowed free access to rodent breeding diet no. 1, expanded (Spratt's Laboratory Services, Barking, Essex). This resulted in a diet with a final fat content of $21 \%$. The second group (untreated, low fat diet group) was fed rodent breeding diet alone, the resultant diet containing 3.5\% fat. Animals were weighed each day and fasted for $24 \mathrm{~h}$ before each experiment. Three experimental protocols were performed on fat-pretreated and untreated rats, during which they were anaesthetised with IP pentobarbitone ( $100 \mathrm{mg} / \mathrm{kg}$ body weight). Blood was collected by cardiac puncture 


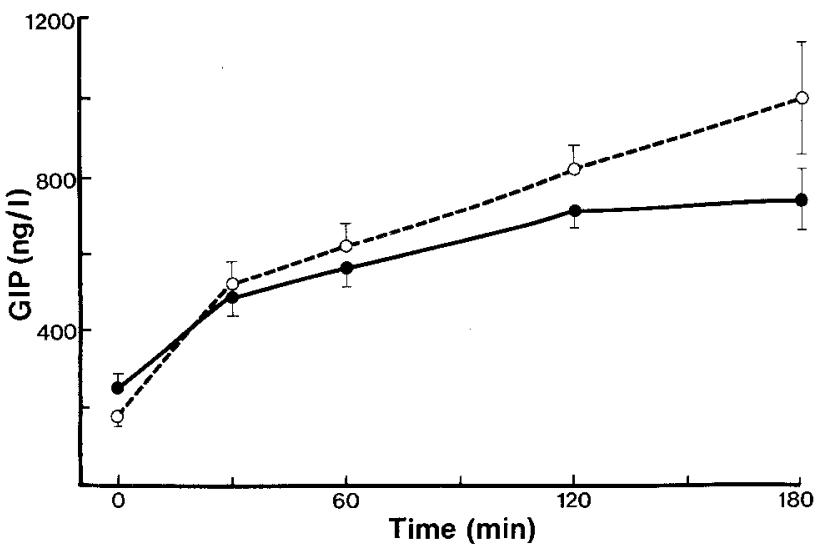

Fig. 1. Plasma GIP levels following oral triolein $(1 \mathrm{ml})$ in fat-pretreated $(\mathrm{O}--\mathrm{O})$ and untreated control rats $(-\bullet)$ (mean $\pm \mathrm{SEM}$, $n=6$ )

into lithium heparin tubes and the samples immediately centrifuged. Plasma for hormone and glucose estimation was divided and stored at $-20^{\circ} \mathrm{C}$.

\section{Experimental Protocols}

Time course of responses to oral fat: Fat-pretreated and untreated groups of rats were each divided into five sets (six rats/set). Set A from each group received no triolein. Animals in the other four sets (B-E) of each group received $1 \mathrm{ml}$ triolein $(8 \mathrm{kcal})$ orally. Blood was collected by cardiac puncture at $0 \mathrm{~min}$ ( $\mathrm{set} \mathrm{A}$ ) and at 30,60,120 and 180 min after oral dosing (sets B-E respectively).

Effect of fat-pretreatment on responses to oral fat with or without IP insulin: Fat-pretreated and untreated rats were each divided into three sets (10 rats/set) and given; set A: $1 \mathrm{ml}$ triolein orally $2 \mathrm{~h}$ before IP insulin $(1 \mathrm{U} / \mathrm{kg}$ body weight $)$; set $\mathrm{B}: 1 \mathrm{ml}$ triolein orally $2 \mathrm{~h}$ before IP saline $(0.154 \mathrm{~mol} / \mathrm{l})$; set C: $1 \mathrm{ml}$ saline $(0.154 \mathrm{~mol} / \mathrm{l})$ orally $2 \mathrm{~h}$ before IP saline. Blood was collected by cardiac puncture $20 \mathrm{~min}$ after the IP injections in all cases.

Effect of fat-pretreatment on the response to oral glucose: Groups of fatpretreated and untreated rats were each divided into two sets (10 rats/ set). Set A was given $3 \mathrm{ml} 2.78 \mathrm{~mol} / 1$ glucose $(5.8 \mathrm{kcal})$ orally and set $B$ $3 \mathrm{ml}$ saline $(0.154 \mathrm{~mol} / \mathrm{l})$ orally. Blood was collected by cardiac puncture $60 \mathrm{~min}$ after oral dosing.

\section{Chemical Analyses}

Immunoreactive insulin was measured by a double-antibody radioimmunoassay using an antiserum raised against bovine insulin (Guildhay Antisera, Guildford, UK, MF/GP/10-VA), iodinated bovine insulin (Radiochemical Centre, Amersham, Bucks., UK) and a rat insulin standard (Novo, Copenhagen, Denmark, lot no. RC 791009). The sensitivity of the assay was $0.5 \mu \mathrm{g} / \mathrm{l}$ and the interassay coefficient of variation $15.6 \%$ at $0.5 \mu \mathrm{g} / \mathrm{l}$ and $6.7 \%$ at $6.0 \mu \mathrm{g} / \mathrm{l}$. [Insulin values are expressed as $\mu \mathrm{g} / 1$ as the rat standard used was calibrated on a weight basis $(1 \mu \mathrm{g}=$ approximately $25 \mathrm{mU})$ ].

Immunoreactive GIP was measured by a double-antibody radioimmunoassay [12]. The antiserum recognizes the larger molecular form of GIP (mol. wt. approximately 8,000 daltons) as well as standard GIP (mol. wt. 4,977). A porcine GIP standard was used, but parallelism was demonstrated between the standard curve and a serially diluted sample of rat plasma containing high levels of endogenous GIP. The assay sensitivity was $110 \mathrm{ng} / 1$ and the interassay coefficient of variation $4.1 \%$ at $2,677 \mathrm{ng} / 1$ and $22.5 \%$ at $138 \mathrm{ng} / 1$.
Plasma glucose was measured using a glucose oxidase method (Beckman glucose analyser) and plasma triglycerides using a fully enzymatic UV kit (Boehringer, Lewis, Sussex).

\section{Statistical Analyses}

Results were compared using Student's t-test for unpaired data and analysis of variance.

\section{Results}

The unpretreated control rats were slightly, but significantly heavier than the fat-pretreated rats throughout the study. There was, however, no significant weight gain in either group of rats on completion of the fat-pretreatment (control rats $297.0 \pm 4.14$ before pretreatment versus $297.5 \pm 4.13 \mathrm{~g}$ after pretreatment, $p$ NS; fat-pretreated rats $280.2 \pm 4.96$ before pretreatment versus $279.0 \pm 10 \mathrm{~g}$ after pretreatment, $p \mathrm{NS}$; mean $\pm \mathrm{SD}$, $n=60$ ). There were no significant differences in fasting plasma glucose, insulin or GIP levels between the two groups on completion of the fat-pretreatment.

\section{Time Course of the Response to Oral Fat}

Mean GIP levels were consistently higher in animals in the fat-pretreated sets, but the differences did not reach statistical significance at any single timepoint (Fig.1). However, when the data was subjected to analysis of variance (two-factor with replication) the two groups were found to be significantly different at the $5 \%$ level.

Plasma triglyceride concentrations were similar in the two groups at the beginning of the experiment but were significantly higher in the fat-pretreated rats than in the controls 120 and $180 \mathrm{~min}$ after receiving oral fat (basal plasma triglyceride concentrations were $0.56 \pm$ 0.04 and $0.42 \pm 0.04 \mathrm{mmol} / 1$ in the control and fat-pretreated groups respectively). At $120 \mathrm{~min}$ plasma triglyceride levels were $2.08 \pm 0.15$ in the control group versus $4.91 \pm 0.84 \mathrm{mmol} / 1$ in the fat-pretreated group, $p<0.01$; at $180 \mathrm{~min}$ they were $2.39 \pm 0.41$ and $7.1 \pm 0.46 \mathrm{mmol} / 1$ respectively $p<0.01$ : mean $\pm \mathrm{SEM}, n=6$ ). The plasma in the fat-pretreated group had a marked lipaemic appearance which was not apparent in the controls.

\section{Effect of Fat Pretreatment on the Response to Oral Fat with or without Exogenous Insulin}

Intraperitoneal insulin was associated with a significantly smaller rise (Fig. 2) in triolein-stimulated GIP secretion in unpretreated rats than in those given IP saline $(663 \pm 49$ versus $853 \pm 93 \mathrm{ng} / 1, p<0.025)$. This difference was not observed in the fat-pretreated rats which showed similar triolein-stimulated GIP levels whether they were given IP insulin or saline $(1008 \pm 95$ versus $1116 \pm 100 \mathrm{ng} / \mathrm{l}$ ). Plasma glucose levels in rats given IP insulin after oral fat fell significantly less in the pretreated than in the unpretreated controls $(2.6 \pm 0.48$ versus 


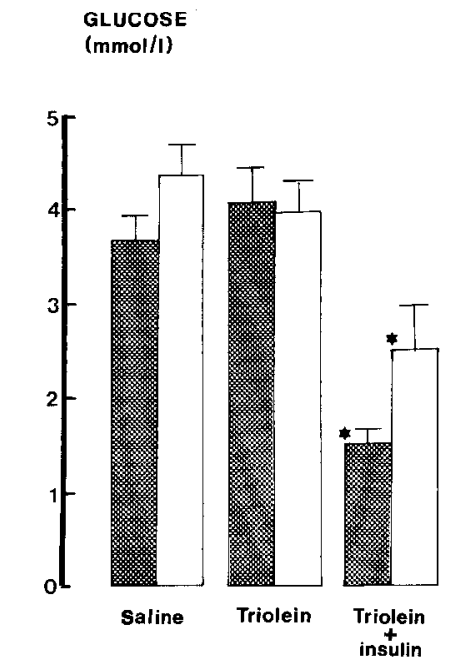

INSULIN
$(\mu \mathrm{g} / \mathrm{I})$
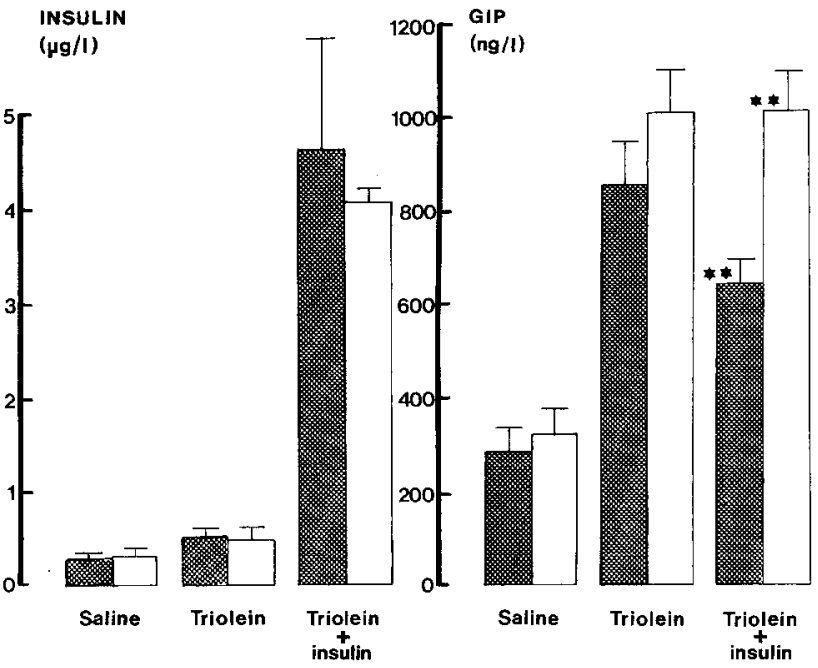

Fig. 2. Plasma glucose, insulin and GIP levels following oral triolein $(1 \mathrm{ml})$ in fat-pretreated $\square$ and untreated control rats (mean $\pm S E M$, $n=10 ; * p<0.05, * * p<0.025)$
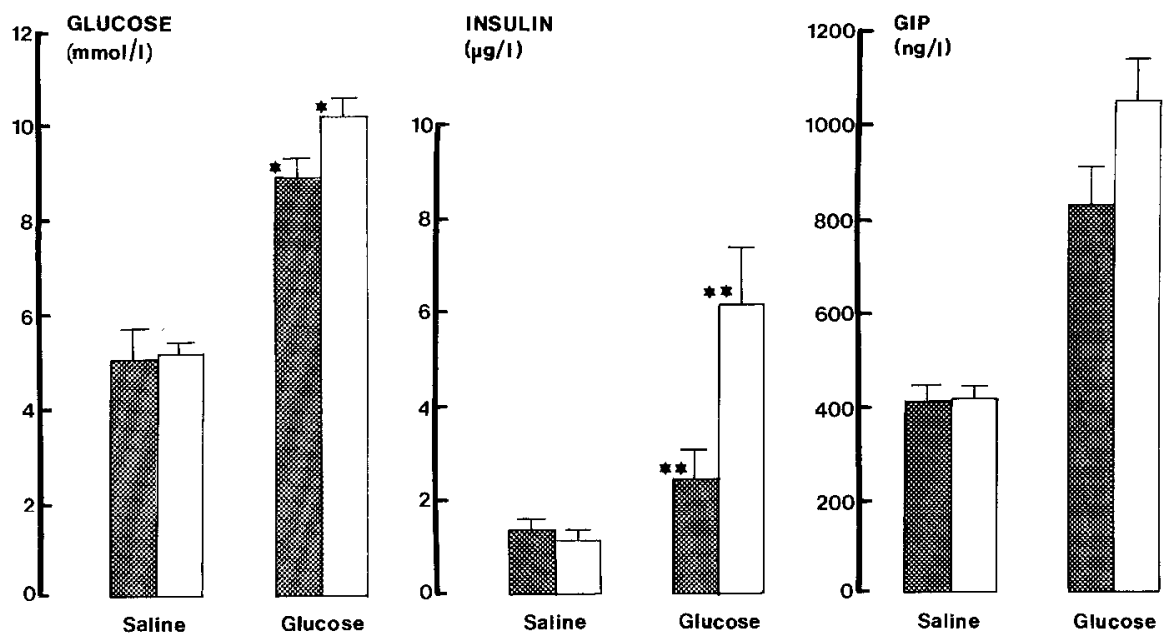

Fig. 3. Plasma glucose, insulin and GIP levels following oral glucose ( $5 \mathrm{mg} / \mathrm{kg}$ body weight) in fat-pretreated $\square$ and untreated control rats (mean \pm SEM, $n=10 ;{ }^{*} p<0.25,{ }^{* *} p<0.01$ )

$1.57 \pm 0.15 \mathrm{mmol} / 1, p<0.05$ ) although plasma insulin levels $20 \mathrm{~min}$ after insulin injection were similar in the two groups ( $4.1 \pm 1.7$ versus $4.7 \pm 1.2 \mu \mathrm{g} / 1, p \mathrm{NS})$.

\section{Effect of Fat Pretreatment on the Response to Oral Glucose}

Following oral glucose, fat-pretreated rats had significantly higher levels of plasma glucose $(10.2 \pm 0.39$ versus $8.9 \pm 0.41 \mathrm{mmol} / 1, p<0.025)$ and insulin $(6.2 \pm 1.2$ versus $2.5 \pm 0.59 \mu \mathrm{g} / 1, p<0.01)$ levels $1 \mathrm{~h}$ after dosing than their untreated controls (Fig. 3). Plasma GIP levels showed a tendency, significant at the $10 \%$ level, to be higher in the fat-pretreated group compared with their untreated controls.

\section{Discussion}

The administration of a high fat diet to rats for 4 days resulted in significantly increased levels of circulating
GIP and triglycerides after dosing with oral triolein. The increased triglyceride levels seen in the fat-pretreated group probably reflect their increased capacity to absorb a large oral fat load. Deschodt-Lanckman et al. [13] showed that pancreatic lipase activity in the rat is stimulated by a high fat diet. An increase in lipase activity in the fat-pretreated group of rats would result in an increase in the rate of absorption of the large oral triolein load. The increased GIP response to oral triolein seen in the fat-pretreated group could be due to their increased rate of fat absorption. GIP secretion apparently depends upon absorption of nutrients and not their mere presence in the intestine $[14,22]$. There is some evidence that the rate of absorption is also a factor in determining the magnitude of the GIP response. A reduction of nutrient absorption rate in certain diseases, untreated coeliac disease or marked malabsorption from any other cause, for example, causes a reduced GIP response to enteric stimuli $[15,16]$ and the addition of the unabsorbable carbohydrate guar to a meal both slows down its rate of absorption and depresses the GIP response [17]. 
Creutzfeldt et al. $[10,11]$ reported an exaggerated GIP response in obese subjects given a high calorie mixed meal. This was not, however, observed in their subjects after 5 days of dietary restriction, although weight loss was minimal. Our data support the concept that composition of the previous diet is more relevant than body weight in determining the magnitude of the GIP response to oral nutrients and is supported by preliminary results obtained in healthy human subjects eating diets of widely different composition.

Various workers $[2,6,18,19]$ have demonstrated that intravenous infusions of either insulin or glucose reduce the rise in plasma GIP provoked by fat ingestion and have suggested the existance of a negative feedback control of insulin upon GIP release. In the present study the control group of rats on a low fat diet showed inhibition of fat-induced GIP release by insulin but the fat-pretreated ones did not. A similar defect in feedback of insulin on GIP secretion has been demonstrated in obese human subjects by Creutzfeldt et al. [10] but was not investigated by Willms et al. [11] in their study of the effects of dietary restriction on GIP secretion in obese subjects.

The abolition of the negative feedback control of insulin on fat-induced GIP release in fat-pretreated rats may be explained by a decreased responsiveness of the GIP-secreting cells to insulin due to a reduction in insulin receptor numbers, though other explanations are possible. Investigation of insulin receptors on human monocytes has shown that insulin receptor number can be altered by dietary changes [20] and that these changes can occur rapidly - within $24 \mathrm{~h}$ [21]. Even a short period of pretreatment made the rats in the present study resistant to the hypoglycaemic action of exogenous insulin. Circulating insulin and glucose levels were also significantly higher after oral glucose in the fat-pretreated animals providing further evidence that the high fat diet predisposed to insulin resistance.

The normal laboratory rat diet contains very little fat, unlike the typical diet consumed by people in the Western World and caution must, therefore, be exercised when assessing the relevance of these findings to man. Nevertheless, the data do provide evidence that diet can be of considerable importance in the development of insulin resistance and changes in activity of the entero-insular axis.

Acknowledgements. P. Kwasowski and K. Tan acknowledge financial support from the Medical Research Council and L. M. Morgan from Guildhay Antisera, University of Surrey.

\section{References}

1. McIntyre N, Holdsworth DJ, Turner DS (1964) New interpretation of oral glucose tolerance. Lancet 2: 20-21

2. Brown JC, Dryburgh JR, Ross SA, Dupre J (1975) Identification and actions of gastric inhibitory polypeptide. Recent Prog Horm Res 31: 487-532

3. Cataland S, Crockett SE, Brown JC, Mazzaferri EL (1974) Gastric inhibitory polypeptide (GIP) stimulation by oral glucose in man. $\mathrm{J}$ Clin Endocrinol Metab 39: 223-228
4. Thomas FB, Mazzaferri EL, Crockett SE, Mekhjian HS, Gruemer HD, Cataland S (1976) Stimulation of secretion of gastric inhibitory polypeptide and insulin by intraduodenal animo acid perfusion. Gastroenterology 70: 523-527

5. Falko JM, Crockett SE, Cataland S, Mazzaferri EL (1975) Gastric inhibitory polypeptide (GIP) stimulated by fat ingestion in man. $J$ Clin Endocrinol Metab 41:260-265

6. Crockett SE, Cataland S, Falko JM, Mazzaferri EL (1976) The insulinotropic effect of endogenous gastric inhibitory polypeptide in normal subjects. J Clin Endocrinol Metab 42: 1098-1103

7. Dryburgh JR, Hampton SM, Marks V (1980) Endocrine pancreatic control of the release of gastric inhibitory polypeptide. Diabetologia 19:397-401

8. Karam JH, Grodsky GM, Forsham PH (1963) Excessive insulin response to glucose in obese subjects as measured by immunochemical assay. Diabetes 12: 197-205

9. Ebert R, Willms B, Brown JC, Creutzfeldt W (1976) Serum gastric inhibitory polypeptide (GIP) levels in obese subjects and after weight reduction. Eur J Clin Invest 6:327

10. Creutzfeldt W, Ebert R, Willms B, Frerichs H, Brown JC (1978) Gastric inhibitory polypeptide (GIP) and insulin in obesity: increased response to stimulation and defective feedback control of serum levels. Diabetologia 14: 15-24

11. Willms B, Ebert R, Creutzfeldt W (1978) Gastric inhibitory polypeptide (GIP) and insulin in obesity: II. Reversal of increased responses to stimulation by starvation or food restriction. Diabetologia 14: 379-387

12. Morgan LM, Morris BA, Marks V (1978) Radioimmunoassay of gastric inhibitory polypeptide. Ann Clin Biochem 15: 172-177

13. Deschodt-Lanckman M, Robberecht P, Camus J, Christophe J (1971) Short-term adaptation of pancreatic hydrolases to nutritional and physiological stimuli in adult rats. Biochimie 53: 789-796

14. Sykes S, Morgan LM, English J, Marks V (1980) Evidence for preferential stimulation of gastric inhibitory polypeptide secretion in the rat by actively transported carbohydrates and their analogues. J Endocrinol 85: 201-207

15. Creutzfeldt W, Ebert R, Arnold R, Frerichs H, Brown JC (1976) Gastric inhibitory polypeptide (GIP), gastrin and insulin: response to test meal in coeliac disease and after duodeno-pancreatectomy. Diabetologia 12:279-286

16. Besterman HS, Cook GS, Sarson DL, Christofides N, Bryant MG, Gregor M, Bloom SR (1979) Gut hormones in tropical malabsorption. Br Med J II: 1252-1255

17. Morgan LM, Goulder TJ, Tsiolakis D, Marks V, Alberti KGMM (1979) The effect of unabsorbable carbohydrate on gut hormones: modification of post-prandial GIP secretion by guar. Diabetologia 17: $85-89$

18. Cleator IGM, Gourlay RH (1975) Release of immunoreactive gastric inhibitory polypeptide (IR-GIP) by oral ingestion of food substances. Am J Surg 130: 128-135

19. Verdonk CA, Rizza RA, Nelson RL, Go VLW, Gerich JE, Service FJ (1980) Interaction of fat-stimulated gastric inhibitory polypeptide on pancreatic alpha and beta cell function. J Clin Invest 65 : 1119-1125

20. Pedersen O, Hjollund E, Lindskov HO, Schwartz Sorensen N (1980) Increased insulin receptors on monocytes from insulin dependent diabetics after high starch high fibre diets. Diabetologia 19:306 (Abstract)

21. Schluter KJ, Petersen KG, Kerp L (1980) Rapid changes in insulin binding affinity of monocytes in male and female volunteers after breakfast. Diabetologia 19:313 (Abstract)

22. Ross SA, Shaffer EA (1981) The importance of triglyceride hydrolysis for the release of gastric inhibitory polypeptide. Gastroenterology 80: 108-111

Received: 10 June 1982

and in revised form: 13 September 1982

Mrs. S. M. Hampton

Department of Biochemistry

University of Surrey

Guildford GU2 5XH, UK 